\title{
Isocratic High-Performance Liquid Chromatographic Assay of Olanzapine: Method Development and Validation
}

\author{
K. Basavaiah, ${ }^{1}$ N. Rajendraprasad, ${ }^{2}$ and K. B. Vinay ${ }^{1}$ \\ ${ }^{1}$ Department of Chemistry, University of Mysore, Manasagangotri, Mysore 570 006, India \\ ${ }^{2}$ PG Department of Chemistry, JSS College of Arts, Commerce \& Science, Ooty Road, Karnataka, Mysore 570 025, India \\ Correspondence should be addressed to N. Rajendraprasad; prasadtnpur@gmail.com
}

Received 1 February 2014; Accepted 12 March 2014; Published 3 April 2014

Academic Editors: Z. Aydogmus, A. Bouklouze, G. Erny, A. Garcia Asuero, and W. X. Misiuk

Copyright (c) $2014 \mathrm{~K}$. Basavaiah et al. This is an open access article distributed under the Creative Commons Attribution License, which permits unrestricted use, distribution, and reproduction in any medium, provided the original work is properly cited.

\begin{abstract}
An accurate, precise, sensitive, and rapid isocratic reversed phase high-performance liquid chromatographic (RP-HPLC) method for the analysis of olanzapine (OLP) in bulk drug and in tablets has been developed and validated. Analysis was performed on a $150 \mathrm{~mm} \times 4.6 \mathrm{~mm}, 5 \mu \mathrm{m}$ particle Intersil ODS 3V column with $10 \mathrm{mM}$ disodium hydrogen phosphate buffer (pH 7.4)-acetonitrile $(35: 65)(\mathrm{v} / \mathrm{v})$ as mobile phase at a flow rate of $1.0 \mathrm{~mL} \mathrm{~min}^{-1}$ with UV detection at $254 \mathrm{~nm}$; the constant column temperature was $40^{\circ} \mathrm{C}$. The runtime under these chromatographic conditions was less than $8 \mathrm{~min}$. The calibration plot was linear over the concentration range of $2.5-20.0 \mu \mathrm{g} \mathrm{mL}^{-1}$ with limits of detection and quantification values of 50 and $200 \mathrm{ng} \mathrm{mL}^{-1}$, respectively. The precision and accuracy of the method were assessed by determination of validation data for precision (intraday RSD values of $0.11-0.28 \%$, interday RSD values of $0.15-0.46 \%)$, accuracy (0.87-2.80\% intraday, $0.33-1.80 \%$ interday), and specificity, in accordance with the ICH guidelines. The stability of standard solution and tablet extract was also studied over a period of $24 \mathrm{~h}$. The method was applied for the determination of OLP in tablets with satisfactory results.
\end{abstract}

\section{Introduction}

Olanzapine (OLP), chemically known as 2-methyl-4-(4methyl-1-piperazinyl)-10H-thieno- $[2,3 \mathrm{~b}][1,5]$ benzodiazepine (Figure 1), is the most commonly prescribed second generation neuroleptic agent for the treatment of schizophrenia and other psychotic disorders.

A complete literature survey of analytical methods for OLP is done. Titrimetry [1-3], visible spectrophotometry [2, 4-10], kinetic spectrophotometry [11], UV-spectrophotometry $[1,12]$, and capillary zone electrophoresis and linear voltammetry [12] have been reported for the quantification of OLP in pharmaceuticals. High-performance thin layer chromatography (HPTLC) has been used to quantify OLP in pharmaceuticals [13-15]. Several liquid chromatographic methods have also been reported for the assay of OLP in pharmaceuticals and/or biological materials. High performance liquid chromatography (HPLC) with UV-detection has been applied for the determination of the drug in human blood serum [16-18] and blood plasma [19-21]. The drug in blood plasma/whole blood has also been assayed by HPLC with amperometric [22, 23], coulometric [24], and MS [25, 26] detection. OLP in rat brain is reported to have been determined by HPLC with coulometric detection [27] whereas for its assay in breast milk [28], the same technique with electrochemical detection has been employed. HPLC with UVdetection has earlier been used for the assay of OLP in pharmaceuticals when present alone or in combination with fluoxetine. An RP-HPLC method for the determination of OLP and its tablets was presented by Xuejun and Zhonghua [29]. They used ODS $\mathrm{C}_{8}$ column and $0.01 \mathrm{M} \mathrm{KH}_{2} \mathrm{PO}_{4}$-methanolacetonitrile $(1: 1: 1, \mathrm{pH} 8.3)$ as mobile phase with UV detection at $273 \mathrm{~nm}$. The linear range was $0.01-1 \mathrm{mg} \mathrm{mL}^{-1}$. Raggi et al. [12] determined OLP in tablets by HPLC with UVdetection at $260 \mathrm{~nm}$ using a $\mathrm{C}_{18}$ column and a mobile phase consisting of acetonitrile and aqueous tetramethylammonium perchlorate. The RSD of the method was better than $1.8 \%$ and accuracy was between 99.9 and $101.1 \%$. Two rapid and specific reversed phase HPLC methods have been reported by S. Patel and N.J. Patel [15] and Pathak and Rajput [30] for the simultaneous determination of OLP and fluoxetine in their formulations. The first report [15] involves 


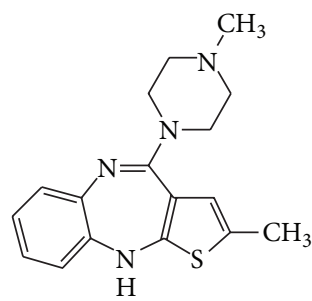

FIgURE 1: Structure of OLP.

the simultaneous determination of fluoxetine $\mathrm{HCl}$ and OLP using reversed-phase liquid chromatography using acetonitrile: methanol:0.032 $\mathrm{M}$ ammonium acetate buffer $(45: 05: 50, \mathrm{v} / \mathrm{v} / \mathrm{v})$ as the mobile phase at a flow rate of $1.5 \mathrm{~mL} \mathrm{~min}^{-1}$. Quantitation of OLP was achieved with ultraviolet detection at $235 \mathrm{~nm}$ over concentration range of $0.1-$ $2 \mu \mathrm{g} \mathrm{mL}^{-1}$ OLP, whereas the second report [30] describes the separation procedure using an Intersil $\mathrm{C}_{18}$ reversed phase column $(150 \mathrm{~mm} \times 4.6 \mathrm{~mm}, 5 \mu \mathrm{m})$ with a $40: 30: 30(\mathrm{v} / \mathrm{v} / \mathrm{v})$ mixture of $9.5 \mathrm{mM} \mathrm{NaH}_{2} \mathrm{PO}_{4}(\mathrm{pH}$ adjusted to $6.8 \pm 0.1$ with triethylamine), acetonitrile, and methanol as mobile phase. The flow rate was $1.2 \mathrm{~mL} \mathrm{~min}^{-1}$ with UV-detection at $225 \mathrm{~nm}$. The calibration plot was linear from 25 to $75 \mu \mathrm{g} \mathrm{mL} L^{-1}$ for OLP. Simultaneous assay of OLP and fluoxetine in tablets by HPLC has also been reported by Reddy et al. [31]. The separation was achieved on a Lichrospher $100 \mathrm{RP}-180 \mathrm{C}_{18}$ column $(250 \mathrm{~mm} \times$ $4.00 \mathrm{~mm}$ id, $5 \mu \mathrm{m})$ using $0.05 \mathrm{M} \mathrm{KH}_{2} \mathrm{PO}_{4}$ buffer $(\mathrm{pH} 5.6$ adjusted with o-phosphoric acid)-acetonitrile (50:50) as the mobile phase at a flow rate of $1 \mathrm{~mL} \mathrm{~min}^{-1}$ and at ambient temperature. Quantitation was achieved by measuring UV absorption at $233 \mathrm{~nm}$ over the concentration range of 10$70 \mu \mathrm{g} \mathrm{mL}^{-1}$. The reported HPLC methods, however, are either poorly sensitive [29] or have narrow linear concentration ranges $[15,30,31]$. The present team of workers has [32] reported the oxidative degradation of the OLP degradation product and the identification and characterization of the degradation products. The objective of this work was to develop a simple, rapid, accurate, and precise HPLC method for quantitative analysis of OLP in tablets and to validate the method in accordance with ICH guidelines [33].

\section{Methods}

2.1. HPLC Instrumentation and Chromatographic Conditions. HPLC analysis was performed with a Waters HPLC system equipped with Alliances 2695 series low pressure quaternary gradient pump, a programmable variable wavelength UVvisible detector, and autosampler. Data were collected and processed using Waters Empower 2 software.

Chromatographic separation was achieved on a $150 \mathrm{~mm} \times$ $4.6 \mathrm{~mm}$ i.d., $5 \mu \mathrm{m}$ particle Intersil ODS $3 \mathrm{~V}$ column. The mobile phase was a 35:65 (v/v) mixture of $10 \mathrm{mM}$ disodium hydrogen phosphate ( $\mathrm{pH} 7.4)$-acetonitrile. The flow rate was fixed as $1.0 \mathrm{~mL} \mathrm{~min}^{-1}$, and UV-detection was performed at $254 \mathrm{~nm}$. Before use, the mobile phase was filtered through $0.2 \mu \mathrm{m}$ filter. The column temperature was maintained at $40^{\circ} \mathrm{C}$.
2.2. Chemicals and Reagents. A sample of OLP, certified to be 99.88\% pure, was obtained as gift from Cipla India Ltd, Mumbai, India. HPLC-grade acetonitrile, disodium hydrogen phosphate, and orthophosphoric acid were purchased from Merk, Mumbai, India. Olanzapine tablets of two different brands, Oleanz (2.5 and 7.5 mg OLP per tablet) and Olanex (10 and $15 \mathrm{mg}$ OLP per tablet) marketed by Sun Pharmaceuticals Industries Ltd, Mumbai, India, and Ranbaxy Laboratories Ltd (Solus), Haryana, India, respectively, were purchased from local commercial sources. HPLC-grade water from Merck was used to prepare all solutions. All other chemicals and reagents used were of analytical grade and purchased from S.D fine chemicals, Mumbai, India.

A buffer solution of $\mathrm{pH} 7.4$ was prepared by adjusting the $\mathrm{pH}$ of $10 \mathrm{mM}$ disodium hydrogen phosphate with orthophosphoric acid. The mobile phase was prepared by mixing the buffer and acetonitrile in $35: 65(\mathrm{v} / \mathrm{v})$ ratio. The diluent was a mixture of water and acetonitrile $(55: 45, \mathrm{v} / \mathrm{v})$.

A stock solution of OLP $\left(100 \mu \mathrm{g} \mathrm{mL}^{-1}\right)$ was prepared in the diluent. Standard solutions were prepared by dilution of the stock solution with the diluent solutions to get solution in the concentration range from 2.5 to $20 \mu \mathrm{g} \mathrm{mL}^{-1}$ OLP.

\subsection{Procedures}

2.3.1. Calibration Graph. Twenty $\mu \mathrm{L}$ of working standard solutions $\left(2.5-20 \mu \mathrm{g} \mathrm{mL}^{-1}\right.$ OLP) was injected automatically into the column in triplicate and the chromatograms were recorded. The calibration graph was prepared by plotting the mean peak area versus concentration in $\mu \mathrm{g} \mathrm{mL}^{-1}$.

2.3.2. Procedure for Tablets. Twenty tablets were accurately weighed and crushed into a fine powder and mixed using a mortar and pestle. A quantity of tablet powder equivalent to $10 \mathrm{mg}$ of OLP was weighed accurately into a $100 \mathrm{~mL}$ calibrated flask, $50 \mathrm{~mL}$ of diluent solution was added and sonicated for 20 min to complete dissolution of the OLP, and the solution was then diluted to the mark with the diluent and mixed well. A small portion of the tablet solution (say $10 \mathrm{~mL}$ ) was withdrawn and filtered through a $0.2 \mu \mathrm{m}$ filter to ensure the absence of particulate matter. The filtrate was appropriately diluted with the diluent before injection into the column.

\section{Results and Discussion}

Drug quality control, stability, metabolism, pharmacokinetics, and toxicity studies all necessitate the determination of drugs in pharmaceutical formulations and biological samples. Consequently, efficient and validated methods are very crucial requirements for all these investigations.

3.1. Method Development and Optimization. Chromatographic parameters were preliminarily optimized to develop the present method for the determination of OLP with short analysis time ( $<8 \mathrm{~min})$, because rapid and economic analysis is becoming increasingly important in pharmaceutical analysis to increase the sample throughput. In the present case, an Intersil ODS $3 \mathrm{~V}$ column maintained at $40^{\circ} \mathrm{C}$ was 


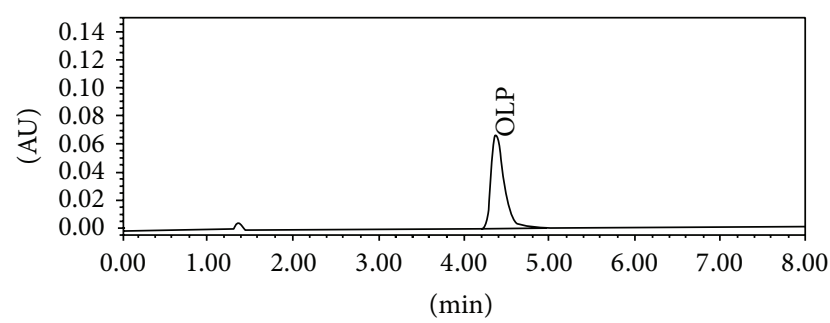

FIGURE 2: Typical chromatogram for $12.5 \mu \mathrm{g} \mathrm{mL} L^{-1}$ OLP under optimized conditions.

used for method development. The mobile phase, $10 \mathrm{mM}$ $\mathrm{Na}_{2} \mathrm{HPO}_{4}(\mathrm{pH} 7.4)$-acetonitrile, $35: 65(\mathrm{v} / \mathrm{v})$ at a flow rate of $1.0 \mathrm{~mL} \mathrm{~min}^{-1}$ was selected, after several preliminary investigatory chromatography runs. Under the experimental conditions described, the peak was well defined and free from tailing (Figure 2). The retention time $\left(R_{T}\right)$ and asymmetry factor were $4.39 \pm 0.01$ and 1.2 , respectively.

3.2. Method Validation. The developed method was validated for linearity, accuracy and precision, limit of detection (LOD), limit of quantification (LOQ), specificity, robustness, and ruggedness in accordance with ICH guidelines.

3.2.1. Linearity. Linearity was studied by preparing standard solutions of different concentrations from 2.5 to $20 \mu \mathrm{g} \mathrm{mL}^{-1}$, plotting a graph of mean peak area three injections against concentration and determining the linearity by least-square regression. The calibration plot was linear over the concentration range $2.5-20.0 \mu \mathrm{g} \mathrm{mL} \mathrm{m}^{-1}(n=7)$.

The regression equation was $y=55739.9 \mathrm{C}-16612.54$, where $y$ is the mean peak area and $x$ is concentration of OLP in $\mu \mathrm{g} \mathrm{mL}^{-1}$ with a mean regression coefficient $(r)$ of 0.9999 . The standard error (SE) of slope and intercept were 288.4 and 4837.6, respectively.

3.2.2. Specificity. The specificity of an analytical method may be defined as the ability to unequivocally determine the analyte in the presence of additional components such as impurities, degradation products, and matrix [34-36]. The specificity was evaluated by injecting the analytical placebo and it was found that the signal measured was caused only by the analyte. A placebo blank containing starch, acacia, hydroxyl cellulose, sodium citrate, talc, magnesium stearate, and sodium alginate was made and its solution was prepared as described under "tablets" and injected. The resulting chromatogram is shown in Figure 3. To identify the interference by the inactive ingredients (excipients), a mixture of placebo and pure OLP was prepared and a suitable aliquot after filtration and appropriate dilution was injected into the column. The obtained chromatogram did not show any other peaks which confirmed the specificity of the method. In addition, the slope of the calibration graph for standards was compared with that prepared from tablet solutions. It was found that there was no significant difference between the slopes, which indicated that the excipients did not interfere with OLP.

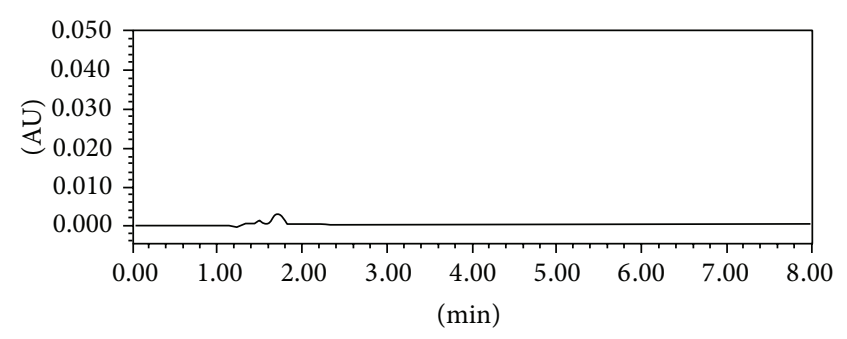

FIGURE 3: Chromatogram obtained for placebo blank under optimized conditions.

\subsubsection{Detection and Quantification Limits (LOD and LOQ).}

The LOD and LOQ were calculated using signal-to-noise ratio method [34-36]. LOD was taken as the concentration of the analyte where the signal-to-noise ratio was 3 , and it was found to be $50 \mathrm{ng} \mathrm{mL}^{-1}$. LOQ defined as the analyte concentration at a signal-to-noise ratio of 10 was found to be $200 \mathrm{ng} \mathrm{mL}{ }^{-1}$. These values indicate that the method is suitable for detection and quantification of OLP over a wide range of concentrations.

3.2.4. Precision. The precision of the method was evaluated in terms of intermediate precision (intraday and interday) [3436]. Solutions of three different concentrations of OLP were analysed in seven replicates during the same day (intraday precision) and five consecutive days (interday precision). Within each series, every solution was injected in triplicate. The RSD values of intraday studies $(<0.3 \%)$ showed that the precision of the method was good. The results of this study are given in Table 1. The interday precision was somewhat poor with the RSD values in the range $0.15-0.46 \%$ (Table 1 ).

Precision of injection repeatability was also examined by analyzing seven injections of solution containing 5.0, 10.0, and $15.0 \mu \mathrm{g} \mathrm{mL}^{-1}$ OLP. The RSDs were calculated from the peak areas and retention times. The results of this study are also complied in Table 1, and the RSD values were found to be less than 0.21 and $0.31 \%$, respectively.

3.2.5. Accuracy. The accuracy of an analytical method expresses the closeness between the reference value and found value [34-36]. Accuracy was evaluated as percentage relative error (RE, \%) between the measured mean concentrations and taken concentrations. The results obtained for three different concentrations are shown in Table 1 from which the accuracy is $<3 \%$. The accuracy was also assessed by analyzing the synthetic mixture (prepared by adding accurately weighed amount of OLP to the placebo), and the calculated percent recovery of OLP was found to be $98.48 \pm 0.64 \%(n=5)$ (values not mentioned) indicating that the common tablet excipients like talc, starch, gum acacia, lactose, hydroxyl methyl cellulose, sodium alginate, and magnesium stearate did not interfere in the assay.

3.2.6. Robustness and Ruggedness. The robustness of the method was investigated by making small deliberate changes 
TABLE 1: Intraday and interday accuracy and precision.

\begin{tabular}{lcccccccc}
\hline OLP injected, & \multicolumn{3}{c}{ Intraday accuracy and precision $(n=7)$} & \multicolumn{3}{c}{ Interday accuracy and precision $(n=7)$} \\
$\mu \mathrm{g} \mathrm{mL}^{-1}$ & OLP found $^{\mathrm{a}}, \mu \mathrm{g} \mathrm{mL}^{-1}$ & $\mathrm{RE}, \%$ & $\mathrm{RSD}^{\mathrm{b}}, \%$ & $\mathrm{RSD}^{\mathrm{c}}, \%$ & $\mathrm{OLP}_{\text {found }}^{\mathrm{a}}, \mu \mathrm{gL}^{-1}$ & $\mathrm{RE}^{\%}$ & $\mathrm{RSD}^{\mathrm{b}}, \%$ & $\mathrm{RSD}^{\mathrm{c}}, \%$ \\
\hline 5.0 & 5.14 & 2.80 & 0.11 & 0.11 & 5.09 & 1.8 & 0.15 & 0.16 \\
10.0 & 10.09 & 0.90 & 0.28 & 0.10 & 10.05 & 0.50 & 0.28 & 0.20 \\
15.0 & 15.13 & 0.87 & 0.26 & 0.21 & 15.05 & 0.33 & 0.46 & 0.31 \\
\hline
\end{tabular}

${ }^{\mathrm{a}}$ Mean value of seven determinations.

${ }^{\mathrm{b}}$ Based on peak area.

${ }^{c}$ Based on retention time.

TABLE 2: Results of robustness study (OLP concentration, $10 \mu \mathrm{g} \mathrm{mL}^{-1}$ ).

\begin{tabular}{|c|c|c|c|c|c|c|c|}
\hline \multirow{2}{*}{$\begin{array}{l}\text { Chromatographic } \\
\text { condition }\end{array}$} & \multirow{2}{*}{ Alteration } & \multicolumn{3}{|c|}{ Peak area precision } & \multicolumn{3}{|c|}{ Retention time precision } \\
\hline & & Mean area \pm SD & SE & RSD, \% & Mean $R_{T}{ }^{*} \pm \mathrm{SD}$ & SE & RSD, \% \\
\hline \multirow{3}{*}{$\begin{array}{l}\text { Mobile phase flow } \\
\text { rate }\left(\mathrm{mL} \mathrm{min}^{-1}\right)\end{array}$} & 0.9 & $606358 \pm 0.0058$ & 0.003 & 0.052 & $4.819 \pm 0.004$ & 0.023 & 0.073 \\
\hline & 1.0 & $547577 \pm 0.000$ & 0.000 & 0.000 & $4.364 \pm 0.003$ & 0.002 & 0.070 \\
\hline & 1.1 & $498323 \pm 0.010$ & 0.006 & 0.108 & $3.972 \pm 0.002$ & 0.002 & 0.038 \\
\hline \multirow{3}{*}{$\begin{array}{l}\text { Column temperature } \\
\left({ }^{\circ} \mathrm{C}\right)\end{array}$} & 38 & $546292 \pm 0.025$ & 0.014 & 0.249 & $4.399 \pm 0.020$ & 0.011 & 0.464 \\
\hline & 40 & $548214 \pm 0.006$ & 0.003 & 0.057 & $4.364 \pm 0.001$ & 0.006 & 0.023 \\
\hline & 42 & $548214 \pm 0.020$ & 0.012 & 0.198 & $3.972 \pm 0.002$ & 0.006 & 0.023 \\
\hline
\end{tabular}

${ }^{*}$ Mean value of three injections.

TABLE 3: Results of solution stability studies.

\begin{tabular}{lcccc}
\hline Time, hour & Area $^{*}(n=5)$ & RSD, $\%$ & $R_{T}$ & RSD, $\%$ \\
\hline 0 & 547492 & & 4.355 & \\
8 & 545643 & & 4.351 & \\
16 & 546389 & 0.213 & 4.352 & 0.073 \\
24 & 548279 & & 4.358 & \\
\hline
\end{tabular}

${ }^{*}$ Concentration of OLP: $10 \mu \mathrm{g} \mathrm{mL}{ }^{-1}$.

in the chromatographic conditions $[33,34]$. The chromatographic conditions selected were flow rate $(0.9,1.0$, and $1.1 \mathrm{~mL})$ and the temperature $\left(38,40\right.$, and $\left.42^{\circ} \mathrm{C}\right)$. There was no significant change in the retention time $\left(R_{T}\right)$ when the flow rate or temperature was changed slightly. The values of RSD (Table 2) indicate that the method is robust.

The ruggedness [35] of the method was assessed by comparison of the intraday and interday results for the assay of OLP performed by three analysts in the same laboratory. The RSD for intraday and interday assay of OLP did not exceed $2.8 \%$ indicating the ruggedness of the method.

3.2.7. Solution Stability. To demonstrate the stability of standard solutions and tablet sample solutions during analysis, they were analysed over a period of $24 \mathrm{~h}$. The results showed that, for both the solutions, the $R_{T}$ and peak area of OLP remained almost unchanged (RSD $<0.073 \%$ and $0.213 \%$, resp.) and no significant degradation was observed during this period, suggesting that both the solutions were stable for at least $24 \mathrm{~h}$, which was sufficient for the whole analytical process. The results of this study are shown in Table 3.

3.2.8. Application of the Method for the Analysis of Commercial Tablets. The developed and validated method was applied to the determination of OLP in two brands of tablets containing OLP in four strengths $(2.5,7.5,10$, and $15 \mathrm{mg}$ per tablet $)$ which were available in the local market. Quantification was performed using the regression equation. The results obtained are presented in Table 4 and are in fair agreement with the label claim. The same tablet powder used for assay by the proposed method was used for assay by a literature method [2] for comparison, and the method consisted of the visual titration of the acetous solution of the tablet with acetous perchloric acid in acetic acid medium. The results were compared statistically by applying the Student's $t$-test for accuracy and $F$-test for precision. As shown by the results compiled in Table 4, the calculated $t$-test and $F$ values did not exceed the tabulated values of 2.77 and 6.39 for four degrees of freedom at the $95 \%$ confidence level, suggesting that the proposed HPLC method and the reference method do not differ significantly with respect to accuracy and precision.

The accuracy and validity of the proposed HPLC method were further ascertained by performing recovery experiments. Preanalyzed tablet powder was spiked with pure OLP at three different concentration levels and the total was found by the proposed method. Each determination was repeated three times. The recovery of pure drug added was quantitative (Table 5) and revealed that coformulated substances did not interfere in the determination.

\section{Conclusions}

A simple, rapid, accurate, precise, and sensitive HPLC method with UV-detection was developed for the determination of olanzapine in bulk drug and in tablets. The method was validated for linearity, LOD and LOQ, specificity, accuracy and precision, and robustness and ruggedness as per the 
TABLE 4: Results of assay of tablets.

\begin{tabular}{lccccc}
\hline \multirow{2}{*}{ Tablet brand name } & \multirow{2}{*}{ Nominal amount, mg } & \multicolumn{3}{c}{ Found* (percent \pm SD) } \\
& & Reference method & Proposed method & Student's $t$-value (2.77) & $F$ value (6.39) \\
\hline Oleanz & 2.5 & $101.4 \pm 0.58$ & $100.7 \pm 0.36$ & 2.36 & 2.59 \\
Oleanz & 7.5 & $98.36 \pm 0.72$ & $98.84 \pm 0.28$ & 1.52 & 6.61 \\
Olanex & 10.0 & $97.75 \pm 0.82$ & $98.16 \pm 0.52$ & 2.97 & 2.09 \\
& 15.0 & $102.3 \pm 0.42$ & $101.6 \pm 0.64$ & 2.32 \\
\hline
\end{tabular}

${ }^{*}$ Mean value of five determinations.

Figures in the parenthesis are the tabulated values for four degrees of freedom at $95 \%$ confidence level.

TABLE 5: Results of recovery study.

\begin{tabular}{lcccc}
\hline Tablet studied & OLP in tablet $\mu \mathrm{g} \mathrm{mL}^{-1}$ & Pure OLP added, $\mu \mathrm{g} \mathrm{mL}^{-1}$ & ${\text { Total found, } \mu \mathrm{g} \mathrm{mL}^{-1}}^{\text {Pure OLP recovered }^{*}(\text { percent } \pm \mathrm{SD} \text { ) }}$ \\
\hline \multirow{3}{*}{ Oleanz (7.5 mg) } & 9.88 & 5.0 & 14.86 & $99.60 \pm 1.2$ \\
& 9.88 & 7.5 & 17.46 & $101.1 \pm 0.86$ \\
\hline \multirow{3}{*}{ Olonex (15 mg) } & 9.88 & 10.0 & 20.10 & $102.2 \pm 0.54$ \\
& 10.16 & 5.0 & 15.34 & $103.6 \pm 0.73$ \\
& 10.16 & 7.5 & 17.75 & $101.2 \pm 0.92$ \\
\end{tabular}

${ }^{*}$ Mean value of three experiments.

ICH guidelines. The retention time of $<5$ min enables rapid determination of drug, which is important in routine analysis. The other advantages of the method are high sensitivity (LOD, $50 \mathrm{ng} \mathrm{mL}^{-1}$ ) and wide linear dynamic range compared to other reported HPLC methods for the drug. The method can also be used to study the stability of solutions. The method sounds suitable for the quality control in pharmaceutical industry because of its simplicity, sensitivity, selectivity, and high accuracy and precision besides being robust and rugged.

\section{Conflict of Interests}

The authors declare that there is no conflict of interests regarding the publication of this paper.

\section{Acknowledgments}

The authors are grateful to Cipla India Ltd, Mumbia, India, for providing the pure sample of olanzapine as gift. One of the authors (N. Rajendraprasad) thanks the J.S.S. Mahavidyapeeta for providing platform and support to pursue research work.

\section{References}

[1] S. Firdous, T. Aman, and A.-U. Nisa, "Determination of olanzapine by UV spectrophotometry and non-aqueous titration," Journal of the Chemical Society of Pakistan, vol. 27, no. 2, pp. 163-167, 2005.

[2] K. Basavaiah and S. A. M. Abdulrahman, "Sensitive and selective methods for the determination of olanzapine in pharmaceuticals using N-bromosuccinimide and two dyes," International Journal of ChemTech Research, vol. 2, no. 1, pp. 660-668, 2010.
[3] K. Basavaiah, N. Rajendraprasad, and K. B. Vinay, "Microtitrimetric determination of a drug content of pharmaceuticals containing olanzapine in non-aqueous medium," Chemical Industry and Chemical Engineering Quarterly, vol. 15, no. 2, pp. 77-81, 2009.

[4] A. Jasiñska and E. Nalewajko, "Batch and flow-injection methods for the spectrophotometric determination of olanzapine," Analytica Chimica Acta, vol. 508, no. 2, pp. 165-170, 2004.

[5] A. Krebs, B. Starczewska, H. Puzanowska-Tarasiewicz, and J. Śledź, "Spectrophotometric determination of olanzapine by its oxidation with N-bromosuccinimide and cerium(IV)sulfate," Analytical Sciences, vol. 22, no. 6, pp. 829-833, 2006.

[6] N. Rajendraprasad, K. Basavaiah, K. Tharpa, and K. B. Vinay, "Quantitative determination of olanzapine in tablets with visible spectrophotometry using cerium(IV)sulphate and based on redox and complexation reactions," Eurasian Journal of Analytical Chemistry, vol. 4, pp. 193-203, 2009.

[7] N. Rajendraprasad and K. Basavaiah, "Highly sensitive spectrophotometric determination of olanzapine using cerium(IV) and iron(II) complexes of 1,10-phenanthroline and 2,2' bipyridyl," Journal of Analytical Chemistry, vol. 65, no. 5, pp. 482-488, 2010.

[8] K. Basavaiah, A. M. A. Sameer, and K. B. Vinay, "New extractive spectrophotometric methods for the determination of olanzapine in pharmaceutical formulatins using bromocresol green," Jordan Journal of Chemistry, vol. 5, pp. 101-117, 2010.

[9] N. Rajendraprasad and K. Basavaiah, "Determination of olanzapine by spectrophotometry using permanganate," Brazilian Journal of Pharmaceutical Sciences, vol. 45, no. 3, pp. 539-550, 2009.

[10] K. Basavaiah, K. Tharpa, N. Rajendraprasad, S. G. Hiriyanna, and K. B. Vinay, "Spectrophotometric determination of antipsychotic drug olanzapine in pharmaceuticals," Jordan Journal of Chemistry, vol. 4, no. 1, pp. 65-76, 2009.

[11] A. A. Mohamed, "Kinetic and maximum-absorbance spectrophotometric methods for the determination of olanzapine," Monatshefte für Chemie, vol. 139, no. 9, pp. 1005-1010, 2008.

[12] M. A. Raggi, G. Casamenti, R. Mandrioli, G. Izzo, and E. Kenndler, "Quantitation of olanzapine in tablets by HPLC, CZE, 
derivative spectrometry and linear voltammetry," Journal of Pharmaceutical and Biomedical Analysis, vol. 23, no. 6, pp. 973981, 2000.

[13] R. B. Patel, M. R. Patel, K. K. Bhari, and B. G. Patel, "Development and validation of an HPTLC method for determination of olanzapine in formulations," Journal of AOAC International, vol. 93, no. 3, pp. 811-819, 2010.

[14] C. Shah, B. Suhagia, N. Shah, D. Patel, and N. Patel, "Stabilityindicating simultaneous HPTLC method for olanzapine and fluoxetine in combined tablet dosage form," Indian Journal of Pharmaceutical Sciences, vol. 70, no. 2, pp. 251-255, 2008.

[15] S. Patel and N. J. Patel, "Simultaneous RP-HPLC and HPTLC estimation of fluoxetine hydrochloride and olanzapine in tablet dosage forms," Indian Journal of Pharmaceutical Sciences, vol. 71, no. 4, pp. 477-480, 2009.

[16] O. V. Olesen and K. Linnet, "Determination of olanzapine in serum by high-performance liquid chromatography using ultraviolet detection considering the easy oxidability of the compound and the presence of other psychotropic drugs," Journal of Chromatography B: Biomedical Applications, vol. 714, no. 2, pp. 309-315, 1998.

[17] H. Weigmann, S. Härtter, S. Maehrlein et al., "Simultaneous determination of olanzapine, clozapine and demethylated metabolites in serum by on-line column-switching high-performance liquid chromatography," Journal of Chromatography $B$ : Biomedical Sciences and Applications, vol. 759, no. 1, pp. 63-71, 2001.

[18] O. V. Olesen, B. Poulsen, and K. Linnet, "Fully automated online determination of olanzapine in serum for routine therapeutic drug monitoring," Therapeutic Drug Monitoring, vol. 23, no. 1, pp. 51-55, 2001.

[19] C. D’Arrigo, G. Migliardi, V. Santoro, and E. Spina, "Determination of olanzapine in human plasma by reversed-phase highperformance liquid chromatography with ultraviolet detection," Therapeutic Drug Monitoring, vol. 28, no. 3, pp. 388-393, 2006.

[20] L. J. Dusci, L. P. Hackett, L. M. Fellows, and K. F. Ilett, "Determination of olanzapine in plasma by high-performance liquid chromatography using ultraviolet absorbance detection," Journal of Chromatography B: Analytical Technologies in the Biomedical and Life Sciences, vol. 773, no. 2, pp. 191-197, 2002.

[21] M. A. Raggi, G. Casamenti, R. Mandrioli, and V. Volterra, "A sensitive high-performance liquid chromatographic method using electrochemical detection for the analysis of olanzapine and desmethylolanzapine in plasma of schizophrenic patients using a new solid-phase extraction procedure," Journal of Chromatography B: Biomedical Sciences and Applications, vol. 750, no. 1, pp. 137-146, 2001.

[22] M. A. Raggi, G. Casamenti, R. Mandrioli, S. Fanali, D. De Ronchi, and V. Volterra, "Determination of the novel antipsychoticz drug olanzapine in human plasma using HPLC with amperometric detection," Chromatographia, vol. 51, no. 910, pp. 562-566, 2000.

[23] M. A. Raggi, R. Mandrioli, C. Sabbioni, N. Ghedini, S. Fanali, and V. Volterra, "Determination of olanzapine and desmethylolanzapine in the plasma of schizophrenic patients by means of an improved HPLC method with amperometric detection," Chromatographia, vol. 54, no. 3-4, pp. 203-207, 2001.

[24] M. A. Saracino, A. Koukopoulos, G. Sani, M. Amore, and M. A. Raggi, "Simultaneous high-performance liquid chromatographic determination of olanzapine and lamotrigine in plasma of bipolar patients," Therapeutic Drug Monitoring, vol. 29, no. 6, pp. 773-780, 2007.
[25] E. Choong, S. Rudaz, A. Kottelat, D. Guillarme, J.-L. Veuthey, and C. B. Eap, "Therapeutic drug monitoring of seven psychotropic drugs and four metabolites in human plasma by HPLC-MS," Journal of Pharmaceutical and Biomedical Analysis, vol. 50, no. 5, pp. 1000-1008, 2009.

[26] M. Josefsson, M. Roman, E. Skogh, and M.-L. Dahl, "Liquid chromatography/tandem mass spectrometry method for determination of olanzapine and $\mathrm{N}$-desmethylolanzapine in human serum and cerebrospinal fluid," Journal of Pharmaceutical and Biomedical Analysis, vol. 53, no. 3, pp. 576-582, 2010.

[27] M. A. Saracino, O. Gandolfi, R. Dall'Olio, L. Albers, E. Kenndler, and M. A. Raggi, "Determination of Olanzapine in rat brain using liquid chromatography with coulometric detection and a rapid solid-phase extraction procedure," Journal of Chromatography $A$, vol. 1122, no. 1-2, pp. 21-27, 2006.

[28] S. C. Kasper, E. L. Mattiuz, S. P. Swanson, J. A. Chiu, J. T. Johnson, and C. O. Garner, "Determination of olanzapine in human breast milk by high-performance liquid chromatography with electrochemical detection," Journal of Chromatography B: Biomedical Sciences and Applications, vol. 726, no. 1-2, pp. 203209, 1999.

[29] X. Xuejun and T. Zhonghua, "Determination of olanzapine and its tablets by HPLC," Zhongguo Yiyao Gongye Zazhi, vol. 35, pp. 46-48, 2004.

[30] A. Pathak and S. J. Rajput, "Development of a stability-indicating HPLC method for simultaneous determination of olanzapine and fluoxetine in combined dosage forms," Journal of Chromatographic Science, vol. 47, no. 7, pp. 605-611, 2009.

[31] B. V. Reddy, K. V. N. S. Reddy, J. Sreeramulu, and G. V. Kanumula, "Simultaneous determination of olanzapine and fluoxetine by HPLC," Chromatographia, vol. 66, no. 1-2, pp. 111-114, 2007.

[32] C. R. Shah, N. J. Shah, B. N. Suhagia, and N. M. Patel, "Simultaneous assay of olanzapine and fluoxetine in tablets by column high-performance liquid chromatography and highperformance thin-layer chromatography," Journal of AOAC International, vol. 90, no. 6, pp. 1573-1578, 2007.

[33] S. G. Hiriyanna, K. Basavaiah, P. S. K. Goud, V. Dhayanithi, K. Raju, and H. N. Pati, "Identification and characterization of olanzapine degradation products under oxidative stress conditions," Acta Chromatographica, vol. 20, no. 1, pp. 81-93, 2008.

[34] International Conference on Hormonisation of Technical Requirements for Registration of Pharmaceuticals for Human Use, ICH Harmonised Tripartite Guideline, Validation of Analytical Procedures: Text and Methodology Q2(R1), Complementary Guideline on Methodology dated November 1996, ICH, London, UK, 2005.

[35] M. Zeaiter, J.-M. Roger, V. Bellon-Maurel, and D. N. Rutledge, "Robustness of models developed by multivariate calibration. Part I: the assessment of robustness," Trends in Analytical Chemistry, vol. 23, no. 2, pp. 157-170, 2004.

[36] M. Mulholland, "Ruggedness testing in analytical chemistry," Trends in Analytical Chemistry, vol. 7, no. 10, pp. 383-389, 1988. 

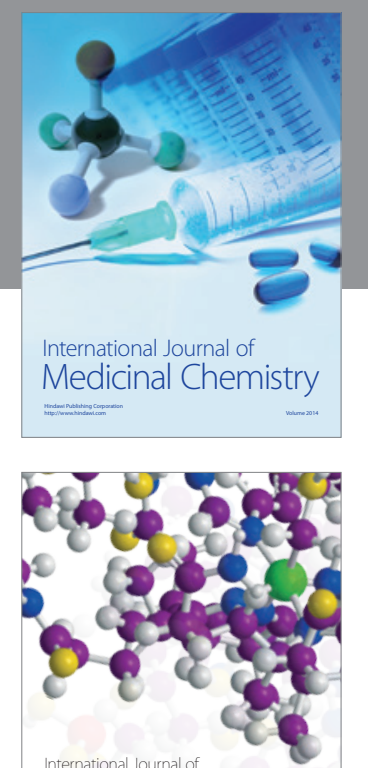

\section{Carbohydrate} Chemistry

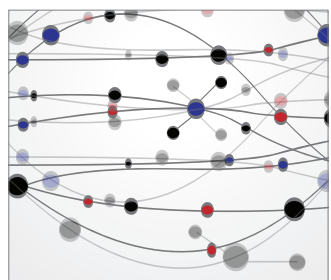

The Scientific World Journal
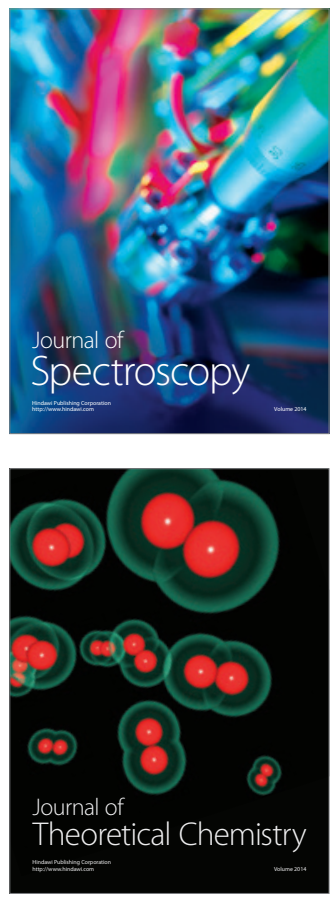
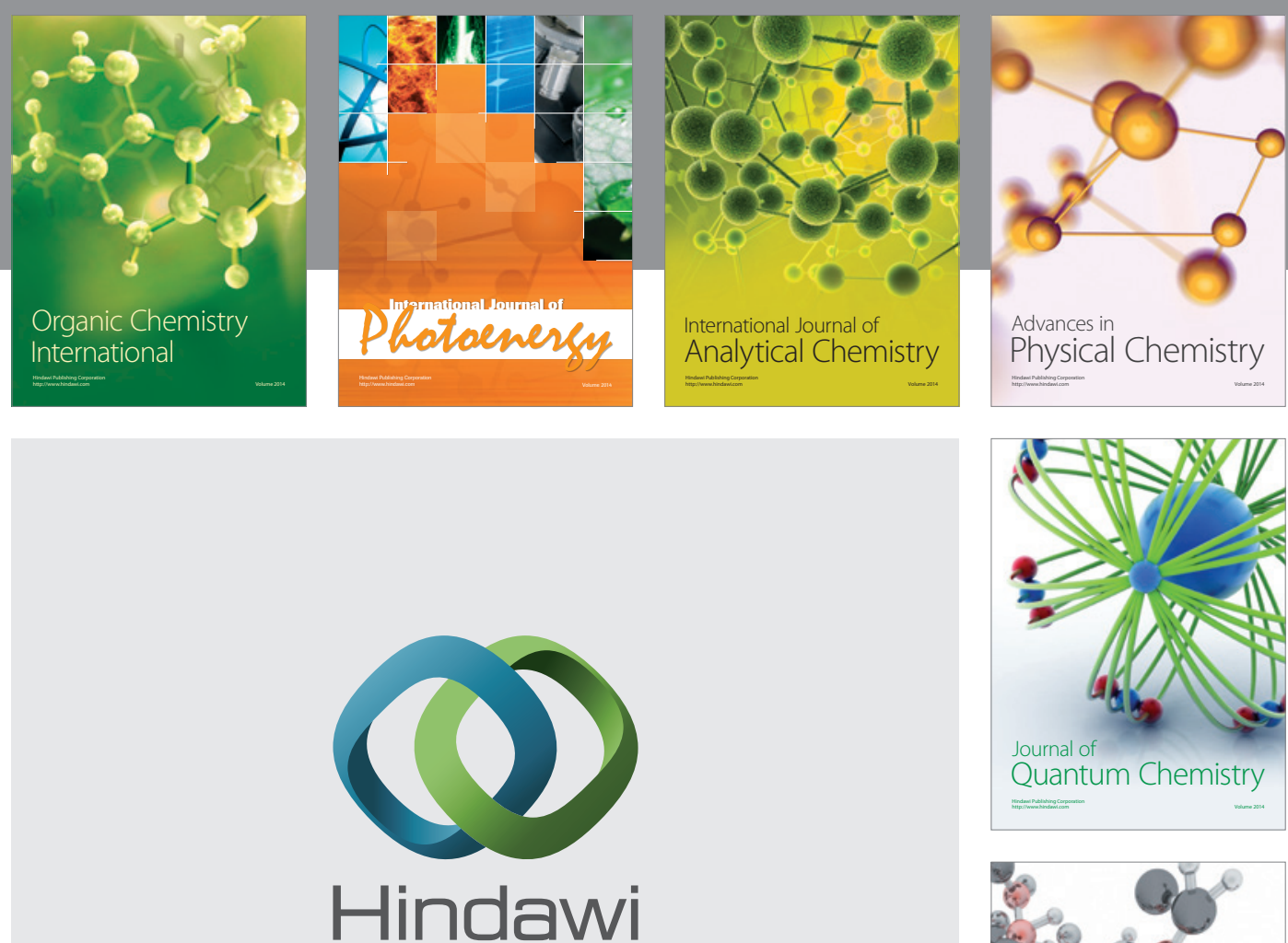

Submit your manuscripts at

http://www.hindawi.com

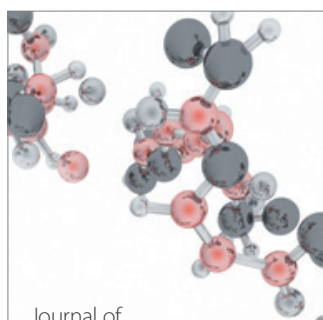

Analytical Methods

in Chemistry

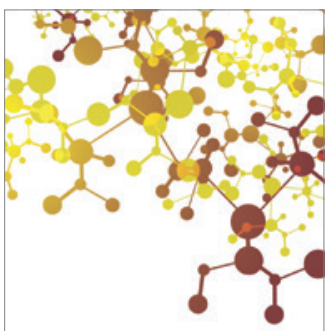

Journal of

Applied Chemistry

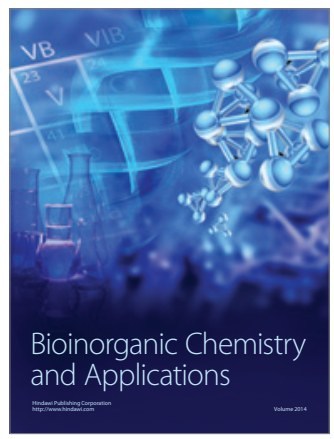

Inorganic Chemistry
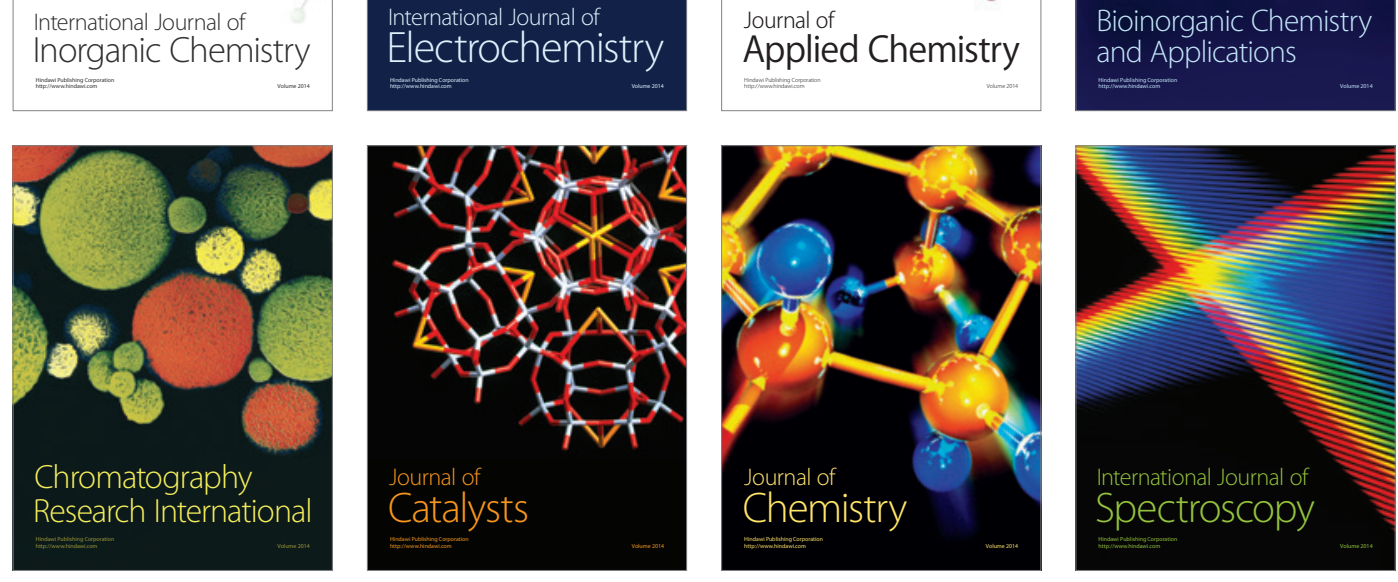